\title{
Correction to: Construction of Medical Equipment-Based Doctor Health Monitoring System
}

\author{
Shaogang Wang ${ }^{1} \cdot$ Shuai Cheng ${ }^{2} \cdot$ Xianghua Zhou ${ }^{2} \cdot$ Yeyun $\mathrm{Mao}^{2} \cdot \mathrm{Ying}^{2} \mathrm{Li}^{2} \cdot \mathrm{Gang}_{\mathrm{L}} \mathrm{Lng}^{2} \cdot \mathrm{Cong} \mathrm{Li}^{1} \cdot \mathrm{Wei}^{\mathrm{Liu}}{ }^{2}$. \\ Xueping Long ${ }^{3}$
}

Published online: 26 April 2019

(C) Springer Science+Business Media, LLC, part of Springer Nature 2019

\section{Correction to: Journal of Medical Systems.} https://doi.org/10.1007/s10916-019-1255-Z

The original version of this article unfortunately contained a mistake. Corrections in equations which were highlighted in a doc file were not carried out.

The original version has been corrected.

Publisher's Note Springer Nature remains neutral with regard to jurisdictional claims in published maps and institutional affiliations.

The online version of the original article can be found at https://doi.org/ 10.1007/s10916-019-1255-z

\footnotetext{
Shaogang Wang

wsg@youcaretech.com

$\triangle$ Gang Long

lg@youcaretech.com
}

1 Department of Urology, Tongji Hospital, Tongji Medical College, Huazhong University of Science and Technology, Wuhan 430030, China

2 YouCare Technology Co., Ltd., Wuhan 430223, China

3 Department of Physics and Astronomy, University of California, Los Angeles, CA 90095, USA 